\title{
Management of Chronic Kidney Disease in an Academic Primary Care Clinic
}

\author{
Ajay Isrania,b Cynthia Korzelius ${ }^{c}$ Raymond Townsend ${ }^{a}$ Douglas Meslerc \\ aRenal-Electrolyte, Hypertension Division and ${ }^{b}$ Center for Clinical Epidemiology and Biostatistics, University of \\ Pennsylvania School of Medicine, Philadelphia, Pa., and ' Renal Division, Boston University School of Medicine, \\ Boston, Mass., USA
}

\section{Key Words}

Chronic kidney disease $\cdot$ Management $\cdot$ Academic setting · Primary care clinic

\begin{abstract}
Background: Three million people in the United States are estimated to have chronic kidney disease (CKD). Management of these CKD patients in the outpatient primary care clinic setting has not been well studied. Hypothesis: Primary care management of CKD can be assessed and opportunities for improvement can be identified. Methods: Management of CKD based on available published literature and guidelines was assessed in a single primary care site of an academic hospital with 23,000 annual visits and 8,300 patients. Charts of patients seen between October 1, 1997 and March 25, 1999 with an elevated $\mathrm{SCr} \geq 1.7 \mathrm{mg} / \mathrm{dl}$ on two separate measurements at least 6 months apart were reviewed for predefined indicators of CKD management. Results: Assessment identified several aspects of CKD management to be suboptimal: control of blood pressure, use of angiotensin-converting enzyme inhibitors or angiotensin receptor blockers, assessment of proteinuria, and renal
\end{abstract}

\section{KARGER}

Fax + 41613061234

E-Mail karger@karger.ch

www. karger.com (c) 2003 S. Karger AG, Basel

Accessible online at www. karger.com/journals/ajn consultation. Better management was found with respect to hemoglobin Alc measurement for diabetic patients. In general, CKD care was similar for diabetic and non-diabetic patients. CKD management was also similar regardless of level of creatinine clearance ( $\geq 50$ vs. $50-30$ vs. $\leq 30 \mathrm{ml} / \mathrm{min}$ ). Conclusion: CKD care can be measured in an outpatient academic primary care clinic and opportunities to improve were identified.

Copyright $($ 2003S. Karger AG, Base

\section{Introduction}

The population prevalence of chronic kidney disease (CKD) is now estimated, depending on the definition of renal insufficiency, from 3 to 20 million in the United States $[1,2]$. While advantages of careful clinical management of this population have been suggested [3, 4], care delivery to this population has historically been 'below the radar', with care quality being assessed infrequently and incompletely $[5,6]$.

Prior to the recent release of the Kidney/Dialysis Outcomes Quality Initiative (K/DOQI) guidelines, few formal recommendations existed for the management of 
patients with CKD [2, 7-10]. However, the clinical literature had already suggested the importance of diabetes management [11], blood pressure control [12-15], angiotensin-converting enzyme inhibition (ACEI) [16], anemia management $[17,18]$, management of calcium metabolism [19-21], and timely referral to nephrologist [4, 5, 22].

Limited literature exists concerning outpatient CKD management [23, 24]. McClellan et al. [7] examined management of CKD patients in the inpatient setting. Kaiser Permanente has reported in a limited way results of its CKD screening and management program, however patients outside of the central practice/lab might not be captured in this laboratory-based program [25]. Nissenson et al. [6] advanced the literature considerably with their analysis of experience with CKD care in a large integrated staff and network model Health Maintenance Organization (HMO) from the Southwestern United States. However, nationwide, only $37.9 \%$ of all insured patients were enrolled in HMOs in 1999 [26]. Management of CKD across providers in an academic primary care clinic has not been described.

In this study we examine how CKD patients were cared for in an academic primary care clinic. We first identified patients with CKD and subsequently evaluated the clinical care they received. A laboratory screen was used to identify patients with elevated serum creatinine from the entire population visiting the clinic over a 12 month period. A chart abstraction tool based on available clinical literature was developed prior to chart review. Charts of patients with renal insufficiency were then examined and clinical data abstracted to measure care performance.

\section{Patients and Methods}

\section{Study Design}

This study was designed as a retrospective analysis of CKD care in an adult primary care site of an academic medical center in Boston with 23,000 visits per year and 8,300 patients. Care at this site is provided by attending physicians and residents under supervision of attending physicians. The study was approved by the Institutional Review Boards of Boston University and University of Pennsylvania. Information on study subjects was obtained from computer records and clinic charts. Using the computerized results of all laboratory tests ordered by the providers, we selected patients who had a serum creatinine ( $\mathrm{SCr}$ ) evaluated between October 1, 1997 and March 25, 1999, and whose creatinine level was $\geq 1.7 \mathrm{mg} / \mathrm{dl}$ on two occasions at least 6 months apart. One hundred and ten patients were identified with a single elevated index SCr. Fifty-six of these patients had a $\mathrm{SCr} \geq 1.7 \mathrm{mg} / \mathrm{dl}$ on two separate measurements at least 6 months apart and thus fit our definition of CKD. This 6-month peri- od and the $\mathrm{SCr} \geq 1.7 \mathrm{mg} / \mathrm{dl}$ was chosen to allow primary care physicians adequate time to optimize the management of the CKD. These 56 patients were selected and their clinic charts were audited. Patients on dialysis were excluded.

\section{Data Abstraction}

Using predesigned forms, patients' charts were reviewed by C.K. for specific indicators of CKD management during the prior 12 months. Data was abstracted from the following sections of the chart: physician progress notes, medication list, and problem list. The demographic data recorded included age, sex, race, weight, and specific diagnosis of hypertension (HTN) or diabetes mellitus (DM). Clinic charts were reviewed for specific indicators such as recognition of CKD as a clinical problem by reviewing problem list or by mention of CKD in the assessment. Clinic charts were also reviewed for history of intolerance to ACEI and angiotension receptor blockers (ARB), use of any anti-hypertensive agents, and request for renal consultation. The following aspects of care were ascertained: systolic and diastolic blood pressure (SBP and DBP), prescription of ACEI or ARB drugs, and use of erythropoietin. Blood pressure readings were recorded from each clinic visit. We averaged the blood pressure readings from all clinic visits during the last 12 months.

Computer records from the 12 months prior to the index $\mathrm{SCr}$ were used to abstract the following data: urinalysis, measurement of microalbuminuria, measurement of spot protein to creatinine ratio, and glycosylated hemoglobin (HbAlc). Data pertaining to serum levels of calcium $(\mathrm{Ca})$, phosphorus $\left(\mathrm{PO}_{4}\right)$, hematocrit $(\mathrm{Hct})$, and albumin (Alb) were abstracted for those patients with a calculated creatinine clearance $(\mathrm{CrCl})$ of $<50 \mathrm{ml} / \mathrm{min}$. We averaged laboratory values for proteinuria, $\mathrm{Hct}, \mathrm{Alb}, \mathrm{Ca}$, and $\mathrm{PO}_{4}$ that were performed during the last 12 months.

\section{Analysis}

We estimated the $\mathrm{CrCl}$ (in $\mathrm{ml} / \mathrm{min}$ ) using the Cockcroft-Gault formula [creatinine clearance $=(140-$ age $) \times$ body weight in $\mathrm{kg} /$ $(\mathrm{SCr} \times 72)]$. The value obtained from this formula was multiplied by 0.85 for female patients. Descriptive variables of patients in the following groups were analyzed: diabetics, non-diabetics, estimated $\mathrm{CrCl} \geq 50 \mathrm{ml} / \mathrm{min}$, estimated $\mathrm{CrCl}$ between 30 and $50 \mathrm{ml} / \mathrm{min}$ and estimated $\mathrm{CrCl} \leq 30 \mathrm{ml} / \mathrm{min}$. These patient groups were defined a priori. Numerical variables are shown as means \pm SD unless otherwise specified. Normally distributed variables were analyzed by $t$ test and ANOVA. Categorical values were analyzed by $\chi^{2}$ tests and by Fischer's exact test when an individual cell size was $<5$. A p value of $<0.05$ was considered statistically significant. Statistical analysis was done using STATA 6.0 [27].

\section{Results}

\section{Demographics}

Fifty-six patients met our criteria for CKD. The demographics of the CKD patient group are shown in table 1. The mean age was $71( \pm 14)$ years and the mean weight was $84( \pm 16) \mathrm{kg}$. Thirty-six percent were female, $43 \%$ were white, $48 \%$ were black, and $9 \%$ were of other races. Twenty-five patients (45\%) had DM and 52 (93\%) had 
HTN. The mean SCr was $2.3( \pm 0.8) \mathrm{mg} / \mathrm{dl}$ and the mean calculated creatinine clearance $(\mathrm{CrCl})$ was $39( \pm 17) \mathrm{ml} /$ min. Seventeen patients $(30 \%)$ had a calculated $\mathrm{CrCl}$ $\leq 30 \mathrm{ml} / \mathrm{min}, 26(46 \%)$ had a calculated $\mathrm{CrCl}$ between 30 and $50 \mathrm{ml} / \mathrm{min}$, and $13(23 \%)$ had a calculated $\mathrm{CrCl}$ $\geq 50 \mathrm{ml} / \mathrm{min}$.

\section{Calculated Creatinine Clearance and Serum \\ Creatinine}

The mean $\mathrm{SCr}$ for the group with the lowest calculated $\mathrm{CrCl}(\leq 30 \mathrm{ml} / \mathrm{min})$ was $3.0( \pm 1.12) \mathrm{mg} / \mathrm{dl}$. This value was significantly larger than the mean $\mathrm{SCr}$ for the other two calculated $\mathrm{CrCl}$ groups $(\mathrm{p}<0.01)$. The $\mathrm{SCr}$ was not statistically different between the two groups with higher calculated $\mathrm{CrCl}$, however. The mean $\mathrm{SCr}$ for the group with calculated $\mathrm{CrCl}$ between 30 and $50 \mathrm{ml} / \mathrm{min}$ and for the group with calculated $\mathrm{CrCl} \geq 50 \mathrm{ml} / \mathrm{min}$ were 2.0 $( \pm 0.29)$ and $1.9( \pm 0.13)$, respectively.

\section{Hypertension and Blood Pressure Control}

We analyzed 243 blood pressure readings, representing an average of four readings per patient during this period (table 1). The mean SBP was $144( \pm 21) \mathrm{mm} \mathrm{Hg}$ and the mean DBP was $80( \pm 11) \mathrm{mm} \mathrm{Hg}$. Twenty-seven (48\%) patients had a mean SBP $>140 \mathrm{~mm} \mathrm{Hg}$ and 8 patients (14\%) had a mean DBP $>90 \mathrm{~mm} \mathrm{Hg}$. On average, 2.6 anti-hypertensive medications were used per patient. Three patients $(5 \%)$ were taking no anti-hypertensive medication. The mean SBP was $>140 \mathrm{~mm} \mathrm{Hg}$ in $31 \%$ of patients with calculated $\mathrm{CrCl} \geq 50 \mathrm{ml} / \mathrm{min}$, in $50 \%$ of patients with calculated $\mathrm{CrCl}$ between 50 and $30 \mathrm{ml} / \mathrm{min}$, and in $59 \%$ of patients with calculated $\mathrm{CrCl} \leq 30 \mathrm{ml} / \mathrm{min}$ $(\mathrm{p}=0.312)$ (fig. 1).

\section{Angiotensin-Converting Enzyme Inhibitor or Angiotensin Receptor Blocker Use}

The frequency of use of angiotensin-converting enzyme inhibitors (ACEI) or angiotensin receptor blockers (ARB) in the entire CKD group was 41\% (23 patients). ACEI or ARB was used in $54 \%$ of patients with calculated $\mathrm{CrCl} \geq 50 \mathrm{ml} / \mathrm{min}$, in $38 \%$ of patients with calculated $\mathrm{CrCl}$ between 50 and $30 \mathrm{ml} / \mathrm{min}$, and in $35 \%$ of patients with calculated $\mathrm{CrCl} \leq 30 \mathrm{ml} / \mathrm{min}$ (fig. 1). The use of ACEI or ARB was not statistically different among these patient groups $(p=0.214)$. The low frequency of ACEI or ARB use could not be completely attributed to intolerance, which was documented in only 10 of the 56 patients $(18 \%)$. Two of the 10 patients with a history of ACEI or ARB intolerance were rechallenged and taking one of these medications at the time of the study.

Management of Chronic Kidney Disease in an Academic Primary Care Clinic
Table 1. Characteristics of patients and the assessment of their care
Number of patients

Mean age, years (SD)

Female, n (\%)

Race

White, $\mathrm{n}(\%)$

Black, n (\%)

Others, $\mathrm{n}(\%)$

Mean $\mathrm{CrCl}, \mathrm{ml} / \mathrm{min}$ (SD)

Patients with $\mathrm{CrCl} 30 \mathrm{ml} / \mathrm{min}, \mathrm{n}(\%)$

Patients with $\mathrm{CrCl}>30$ and $<50 \mathrm{ml} / \mathrm{min}, \mathrm{n}(\%)$

Patients with diabetes, $\mathrm{n}(\%)$

Patients with hypertension, $\mathrm{n}(\%)$

Mean systolic blood pressure, $\mathrm{mm} \mathrm{Hg}$

Mean diastolic blood pressure, $\mathrm{mm} \mathrm{Hg}$

Patients with SBP > $140 \mathrm{~mm} \mathrm{Hg}, \mathrm{n}(\%)$

Patients with DBP $>90 \mathrm{~mm} \mathrm{Hg}, \mathrm{n}(\%)$

ACEI or ARB used, $n(\%)$

ACEI intolerance, $\mathrm{n}(\%)$

Urinalysis done, $\mathrm{n}(\%)$

Proteinuria quantitated, $\mathrm{n}(\%)$

Renal service consulted, n (\%)
56

$71( \pm 14)$

$20(36)$

$24(43)$

$27(48)$

$5(9)$

$39( \pm 17)$

$17(30)$

$26(46)$

$25(45)$

$52(93)$

$144( \pm 21)$

$80( \pm 11)$

$27(48)$

$8(14)$

$23(41)$

$10(18)$

$30(54)$

$11(19)$

$12(21)$
$\mathrm{SD}=$ Standard deviation

\section{Documentation of Chronic Renal Insufficiency as a Problem}

Overall, chronic renal insufficiency (CRI) was recognized and documented in the problem list of $49(88 \%)$ patients. CRI was documented as a problem in $77 \%$ of patients with calculated $\mathrm{CrCl} \geq 50 \mathrm{ml} / \mathrm{min}$, in $92 \%$ of patients with calculated $\mathrm{CrCl}$ between 50 and $30 \mathrm{ml} / \mathrm{min}$, and in $88 \%$ of patients with calculated $\mathrm{CrCl} \leq 30 \mathrm{ml} / \mathrm{min}$ $(p=0.682)$ (fig. 1).

\section{Proteinuria Assessment and Quantification}

Overall, 30 patients (54\%) had a dipstick urinalysis for protein. This is likely an overestimate of the frequency of evaluation of proteinuria because urinalyses were probably done for other indications in some cases. Dipstick urinalysis was checked in $62 \%$ of patients with calculated $\mathrm{CrCl} \geq 50 \mathrm{ml} / \mathrm{min}$, in $42 \%$ of patients with calculated $\mathrm{CrCl}$ between 50 and $30 \mathrm{ml} / \mathrm{min}$, and in $65 \%$ of patients with calculated $\mathrm{CrCl} \leq 30 \mathrm{ml} / \mathrm{min}(\mathrm{p}=0.308)$ (fig. 1). Sixteen patients had an average protein measurement of oneplus or greater on dipstick testing (range for this test negative to four-plus). Eleven patients (19\%) had documented urinary protein quantification by either 24-hour urine, spot urine protein to creatinine ratio, or quantitative

Am J Nephrol 2003;23:47-54 


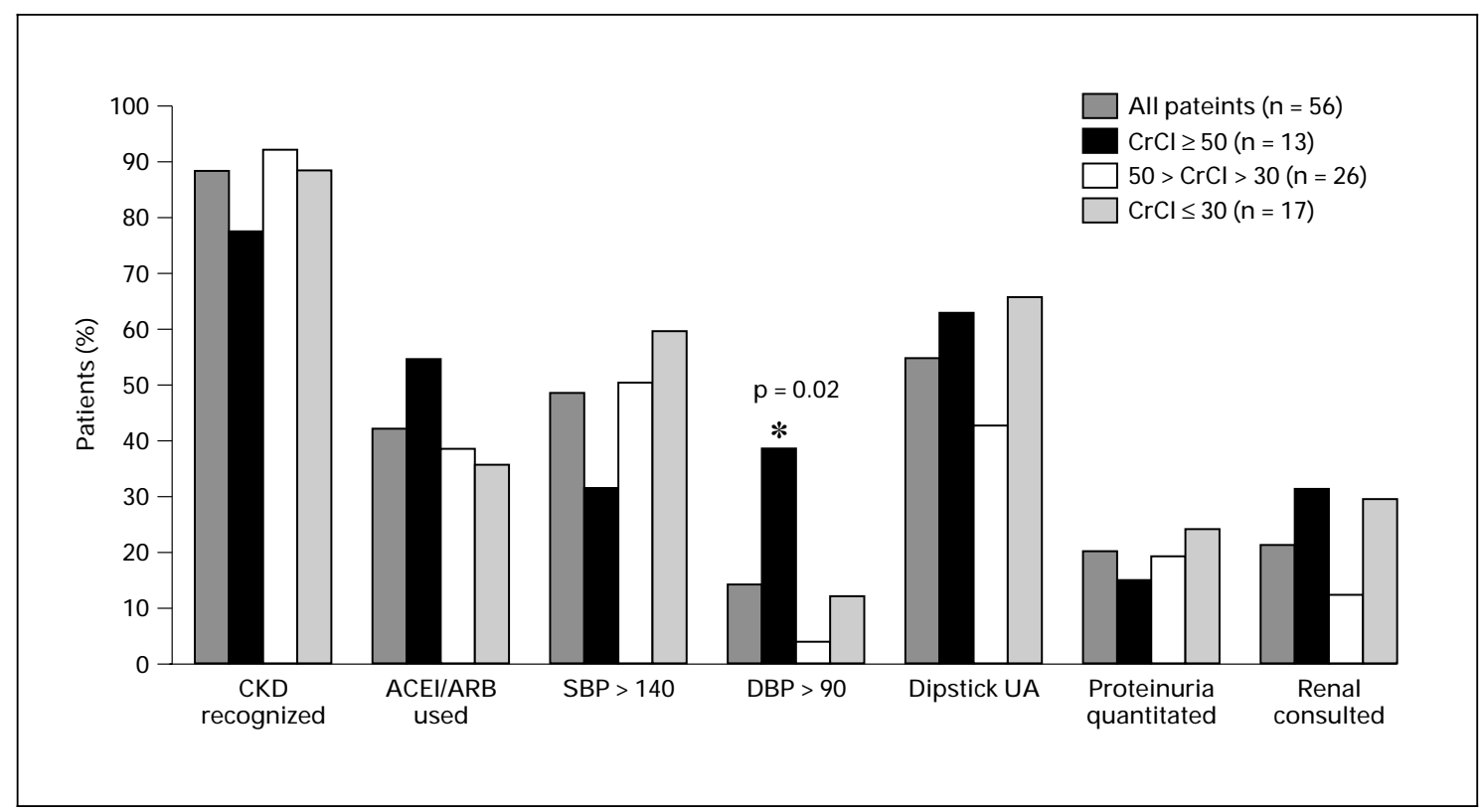

Fig. 1. Management of patients according to different estimated creatinine clearance was not significantly different. Only the percentage of patients with diastolic blood pressure $>90 \mathrm{~mm} \mathrm{Hg}$ (DBP > 90) was statistically different between different creatinine clearance groups $\left({ }^{*} \mathrm{p}=0.02\right.$, Fisher's exact test).

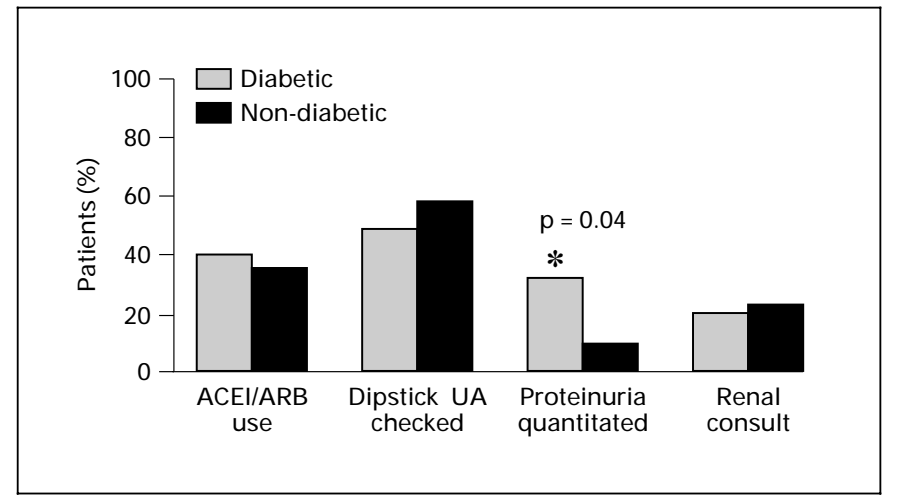

Fig. 2. Management of diabetics versus non-diabetics was not significantly different. Only proteinuria was more likely to be quantified among diabetics $(* \mathrm{p}<0.05$, Fisher's exact test).

microalbuminuria. Urinary protein was quantified in $15 \%$ of patients with calculated $\mathrm{CrCl} \geq 50 \mathrm{ml} / \mathrm{min}$, in $19 \%$ of patients with calculated $\mathrm{CrCl}$ between 50 and $30 \mathrm{ml} / \mathrm{min}$, and in $24 \%$ of patients with calculated $\mathrm{CrCl}$ $\leq 30 \mathrm{ml} / \mathrm{min}(\mathrm{p}=0.914)$ (fig. 1$)$.

\section{Renal Consultation}

Renal consultation was requested for 12 of the 56 patients (21\%); in $31 \%$ of patients with calculated $\mathrm{CrCl}$ $\geq 50 \mathrm{ml} / \mathrm{min}$, in $12 \%$ of patients with calculated $\mathrm{CrCl}$ between 50 and $30 \mathrm{ml} / \mathrm{min}$, and in $29 \%$ of patients with calculated $\mathrm{CrCl} \leq 30 \mathrm{ml} / \mathrm{min}$ ( $\mathrm{p}=0.214$ ) (fig. 1 ).

\section{Management of CKD in Diabetics}

Of the 25 patients with DM, HbA1c was measured in $24(96 \%)$ and the mean value was $8.0 \%( \pm 1.3 \%)$. The mean $\mathrm{SCr}$ did not differ significantly between diabetics and non-diabetics (SCr $2.0 \pm 1.0$ vs. $2.1 \pm 0.8 \mathrm{mg} / \mathrm{dl}$, respectively, $\mathrm{p}=0.68$ ), however the mean $\mathrm{CrCl}$ was significantly lower in diabetics $(33 \pm 13 \mathrm{ml} / \mathrm{min}$ vs. $43 \pm$ $19 \mathrm{ml} / \mathrm{min}, \mathrm{p}=0.03)$. Diabetics and non-diabetics had similar average SBP $(149 \pm 23$ vs. $140 \pm 19 \mathrm{~mm} \mathrm{Hg}, \mathrm{p}=$ 0.12 ), however average DBP was significantly lower in diabetics (77 \pm 10 vs. $82 \pm 10 \mathrm{~mm} \mathrm{Hg}, \mathrm{p}=0.07)$.

ACEI or ARB use was documented in 10 of 25 diabetics $(40 \%)$ and in 11 of 31 non-diabetics $(35 \%)$. This difference was not statistically significant $(p=0.73)$. The rate of ACEI or ARB intolerance was similar in both diabetics and non-diabetics, 16 vs. $19 \%$, respectively $(p=0.74)$ (fig. 2). 
Proteinuria was more likely to be quantified in diabetic patients. Quantification of proteinuria was performed in $8(32 \%)$ diabetics versus $3(10 \%)$ non-diabetics $(\mathrm{p}=$ 0.04 ). Performance rates of dipstick urinalysis and rates of renal consultation were not different between diabetics and non-diabetics (fig. 2).

\section{Additional Care Measures for Calculated $\mathrm{CrCl}$ $<50 \mathrm{ml} / \mathrm{min}$}

Additional analyses were performed for the 43 patients with $\mathrm{CrCl}<50 \mathrm{ml} / \mathrm{min}$ (table 2). Twenty-six patients $(60 \%)$ had their serum calcium level checked (mean $9.1 \pm$ $0.6 \mathrm{mg} / \mathrm{dl}$, normal range $8.4-10.2 \mathrm{mg} / \mathrm{dl}), 13(30 \%)$ had their serum phosphate level checked (mean $3.9 \pm 0.9 \mathrm{mg} /$ $\mathrm{dl}$, normal range $2.7-4.5 \mathrm{mg} / \mathrm{dl})$, and $4(9 \%)$ had their serum albumin checked (mean $4.0 \pm 0.3 \mathrm{mg} / \mathrm{dl}$, normal range $3.5-4.8 \mathrm{mg} / \mathrm{dl})$. The hematocrit was checked in 29 patients $(67 \%)$ and 11 had an average value $<33 \%$ (normal range $40-54 \%$ ). Four of these 11 patients were prescribed erythropoietin. Of these 4 patients, 3 had a calculated $\mathrm{CrCl}$ of $<30 \mathrm{ml} / \mathrm{min}$ and 1 had a calculated $\mathrm{CrCl}$ of $57 \mathrm{ml} / \mathrm{min}$.

\section{Discussion}

The main finding of our study is that the management of CKD patients in an academic medical center does not always conform to recommendations from the published literature. Management of CKD patients was suboptimal for blood pressure control, use of ACEI or ARB, measurement of proteinuria, and rate of renal consultation. In contrast, $\mathrm{HbA} 1 \mathrm{c}$ was measured in most of the diabetics as has been recommended.

The prevalence of CKD in our population is similar to the national prevalence of CKD. The prevalence of $\mathrm{CKD}$, as defined in our study as two elevated $\mathrm{SCr} \geq 1$. $7 \mathrm{mg} / \mathrm{dl}$ at least 6 months apart, is $0.7 \%(56 / 8,300$ patients in clinic). However, the prevalence of CKD in our study population is higher if CKD is defined as a single elevated $\mathrm{SCr} \geq 1.7 \mathrm{mg} / \mathrm{dl}$. If all 110 patients with $\mathrm{SCr}$ $\geq 1.7 \mathrm{mg} / \mathrm{dl}$ are included, the prevalence of CKD rises to $1.3 \%(110 / 8,300$ patients in clinic). This prevalence is comparable to the $1.2 \%$ prevalence described by the National Health and Nutrition Examination Survey III (NHANES). The NHANES data showed that the prevalence of CKD patients with a single $\mathrm{SCr} \geq 1.7 \mathrm{mg} / \mathrm{dl}$ was 3 million (1.2\% of a 250 -million population) [1]. While a less stringent definition of CKD is appropriate for population epidemiologic studies, we felt our more rigorous
Table 2. Laboratory data for patients with $\mathrm{CrCl}<50 \mathrm{ml} / \mathrm{min}$ $(\mathrm{n}=43)$

\begin{tabular}{lc}
\hline Patients who had Ca checked, n (\%) & $26(60)$ \\
Mean Ca level, mg/dl & $9.1( \pm 0.6)$ \\
Patients who had $\mathrm{PO}_{4}$ checked, n (\%) & $13(30)$ \\
Mean $\mathrm{PO}_{4}$ level, mg/dl & $3.9( \pm 0.9)$ \\
Patients who had Hct checked, n (\%) & $29(67)$ \\
Patients with Hct $<33 \%, \mathrm{n}(\%)$ & $11(26)$ \\
Patients who had Alb checked, n (\%) & $4(9)$ \\
Mean Alb level, mg/dl & $4( \pm 0.3)$
\end{tabular}

definition was needed for the evaluation of patterns of clinical care.

Compared to previously described CKD populations, our CKD patients were older and had a significantly higher incidence of HTN and DM [23, 28]. In our CKD patients, the prevalence of HTN was $93 \%$ and the prevalence of DM was $45 \%$, probably due to their high average age of 71 years. In prior published studies of CKD, the prevalence of HTN was $75-87 \%$ and the prevalence of DM $25 \%[23,28]$.

At the time of recruitment into our study (prior to public release of $\mathrm{K} / \mathrm{DOQI}$ for $\mathrm{CKD}$ ) consensus was emerging and recommendations had been published that supported certain routine practices in this population, and specifically in diabetics. In fact, the National Institute of Diabetes and Digestive and Kidney Diseases of the National Institutes of Health had published, in a workshop report, recommendations for the prevention of progression of nephropathy in patients with and without diabetes in 1995 [9]. The workshop recommended blood pressure management to the level suggested in Joint National Committee V (130/85) and to a lower goal of $125 / 75 \mathrm{~mm}$ $\mathrm{Hg}$ for those with $>1 \mathrm{~g} / 24 \mathrm{~h}$ proteinuria (these more aggressive targets were endorsed in the JNC VI recommendations released in 1997), and that proteinuria should be quantitated in diabetics and if present, ACEI considered. From this and other existing recommendations, we chose the following care measures for evaluation in our population: measurement of $\mathrm{HbAlc}$, measurement of proteinuria, control of hypertension, ACEI or ARB use, and measurement of anemia and calcium and phosphorus levels in patients with GFR $<60 \mathrm{ml} / \mathrm{min} / 1.73 \mathrm{~m}^{2}$. The $\mathrm{K} / \mathrm{DOQI}$ guidelines for $\mathrm{CKD}$ released to the public in 2002 subsequently incorporated guidelines similar to all these care measures. Thus, the new K/DOQI guidelines support the CKD care measures used in our study. 
We found the care of CKD was uneven, sometimes conforming to published literature and oftentimes not. The care of CKD was optimal with respect to the assessment of $\mathrm{HbAlc}$. In addition, the recognition of CKD was high at $88 \%$ in our study. However, the indicators of CKD care were suboptimal for the following: control of blood pressure, use of ACEI or ARB, assessment of proteinuria (routine dipstick and quantitative), and rate of renal consultation. Overall, we identified several clinically important differences between the observed care of CKD and previously published recommendations. The majority of primary care physicians had identified CKD as a clinical problem $(88 \%)$, so lack of recognition is not likely the explanation of suboptimal CKD care.

The assessment of $\mathrm{HbAlc}$ in our patients was much better than that in other studies. Ninety-six percent of our diabetic patients had their HbAlc checked, with these patients exhibiting a good level of control. In sharp contrast, Peters et al. [29] reported poor compliance with HbAlc monitoring. Peters et al. analyzed the quality of diabetes care in a large health management organization (HMO). They found that $56 \%$ of diabetics had no HbAlc checked and $40 \%$ of those with measured HbAlc had a level $>10 \%$.

In our CKD patients, the management of blood pressure and the use of ACEI or ARB was suboptimal, although better than that found in some studies. In our group, $48 \%$ of the patients had a SBP $>140 \mathrm{~mm} \mathrm{Hg}$ and $14 \%$ had a DBP $>90 \mathrm{~mm} \mathrm{Hg}$. In contrast, the NHANES cohort had blood pressures that were not well controlled in $73 \%$ of patients [30]. In our study, $41 \%$ of the patients had been treated with an ACEI or ARB. Another 14\% had been tried on these agents but could not tolerate them. Clinical practices have been analyzed in terms of adherence to recommendations for use of ACEI in diabetic patients with HTN or proteinuria. In a chart audit of diabetic patients enrolled in five Arizona Medicare managed care plans, only 23\% of diabetic patients with hypertension were on ACEI. About one-third of the diabetics with gross proteinuria or microalbuminuria were also on ACEI [31]. In a large HMO in New Mexico, only $31 \%$ of CKD patients seen by a nephrologist were on an ACEI [28]. Another group recruiting 133 diabetic patients for a controlled trial of diabetes nurse case management program in a group model HMO found that only $39 \%$ of the study participants were on ACEI [32]. A study of nephrology practices in the Northeastern United States showed that only $49 \%$ of their CKD patients were on an ACEI [23]. However, these prior studies have not reported the prevalence of ACEI or ARB intolerance in their CKD populations.
We expected the management of diabetics in our CKD study to be better than that for non-diabetics due to the predominance of prior literature on proteinuria and blood pressure management in this group $[11,16]$. We found that the DBP was significantly lower in the diabetics, however, the SBP was no better for diabetics than nondiabetics. Overall, the rate of proteinuria assessment by dipstick was low at 54\% and did not differ substantially between diabetic and non-diabetic patients. Other studies report a similarly low rate of proteinuria assessment in HMOs [29, 33].

In our study, proteinuria was quantitated (either by 24hour urine, spot protein to creatinine ratio, or quantitative microalbuminuria) more often in diabetics than in non-diabetics, although the overall rate, even for diabetics, was low. Other studies in diabetics report that proteinuria was quantitated in $5-31 \%$ of HMO patients [31, 32, 34]. We are aware of no other studies which compare proteinuria measurement between diabetic and non-diabetic subgroups.

We expected the management of CKD in our study to be most intense in the group with lowest $\mathrm{CrCl}$. However, the use of ACEI or ARB, assessment of proteinuria, quantification of proteinuria, and rate of renal consultation was not significantly different in those patients with the most advanced renal insufficiency. The low rate of renal consultation, even in the lowest $\mathrm{CrCl}$ group in our CKD study, is consistent with the pattern of late referral for initiation of dialysis documented by others [22, 24].

When the estimated $\mathrm{CrCl}$ was $<50 \mathrm{ml} / \mathrm{min}$, we also looked for other quality of care items such as erythropoietin use, assessment of laboratory parameters for Hct, Alb, $\mathrm{Ca}$, and $\mathrm{PO}_{4}$. We found the measurement of these parameters to be variable ranging from $67 \%$ for Hct to $9 \%$ for serum albumin. When measured, the Hct was $<33 \%$ in $26 \%$ of our patients with a $\mathrm{CrCl}<50 \mathrm{ml} / \mathrm{min}$. A similar level of anemia was reported in $29 \%$ patients with CKD in a large New Mexico HMO [28]. Kausz et al. [23] reported that $38 \%$ of patients had a Hct $<30 \%$ in their analysis of nephrology practices in Northeastern United States. Only 4 of our 11 patients with Hct $<33 \%$ were prescribed supplemental erythropoietin.

This study demonstrates the feasibility of employing selected care measures to examine CKD management practices in a primary care setting. Limitations to generalization of our results exist including the small sample size, the cross-sectional form of the data, and the retrospective nature of the analysis. The use of less stringent criteria for CKD would have increased our sample size but at the expense of specificity. A larger study population could 
also have been generated through examination of a larger primary care population or by observation over a longer period of time. Indeed, this study was neither designed nor powered to evaluate the significance of differences in specific care measures among patient subgroups. However, the study does demonstrate the feasibility of care assessment using standardized abstraction tools, and the potential of this measurement for improving care quality. While cross-sectional analyses do not document care for individual patients across the time continuum, changes in cross-sectional data could reflect changes in practice as applied to individual patients [35].

In conclusion, we found that several aspects of care of CKD patients in this primary care setting were in poor compliance with recommendations from published literature. These included suboptimal control of blood pressure and use of ACEI or ARB and infrequent measurement of proteinuria and rate of renal consultation. The potential for improving care in these areas is illustrated by the excellent compliance with $\mathrm{HbAlc}$ measurement, a care measure for which there has been a strong and consistent message from many groups for nearly a decade. Wellfocused and publicized medical education and quality improvement efforts are needed to improve the quality of CKD care in primary care clinics. Similar standardized abstraction tools may be useful in the future to document changes in practice, for example after the new K/DOQI guidelines for CKD are disseminated to primary care physicians.

\section{Acknowledgements}

A.I. has been supported by NIH F32DK60298-01, and D.M. by NIH K08DK2453. Thanks to Laura Dember, MD, for her constructive comments

\section{References}

1 Jones C, McQuillan G, Kusek J, Eberhardt M, Herman W, Coresh J, Salive M, Jones C, Agodoa L: Serum creatinine in the US population: Third National Health and Nutrition Examination Survey. Am J Kidney Dis 1998;32:992_ 999.

2 Levey A: Part 1. Executive Summary. Am J Kidney Dis 2002;9(suppl 1):17-31.

3 Steinman TI: Kidney protection: How to prevent or delay chronic renal failure. Geriatrics 1996;51:28-35.

4 Ifudu O, Dawood M, Homel P, Friedman E: Excess morbidity in patients starting uremia therapy without prior care by a nephrologist. Am J Kidney Dis 1996;28:841-845.

5 Obrador G, Pereira B: Early referral to the nephrologist and timely initiation of renal replacement therapy: A paradigm shift in the management of patients with chronic renal failure. Am J Kidney Dis 1998;31:398-417.

6 Nissenson A, Pereira B, Collins A, Steinberg E: Prevalence and characteristics of individuals with chronic kidney disease in a large maintenance organization. Am J Kidney Dis 2001;37: 1177-1183

7 McClellan W, Knight D, Karp H, Brown W: Early detection and treatment of renal disease in hospitalized diabetic and hypertensive patients: Important differences between practice and published guidelines. Am J Kidney Dis 1997;29:368-375.

8 Churchill D, Blake P, Goldstein M, Jindal K, Toffelmire E: Clinical Practice Guidelines of the Canadian Society of Nephrology for treatment of patients with chronic renal failure. $\mathrm{J}$ Am Soc Nephrol 1999;10(suppl 13):287-321.

Management of Chronic Kidney Disease in an Academic Primary Care Clinic
9 Jacobson H, Striker G, Group W: Report on a workshop to develop management recommendations for the prevention of progression in chronic renal disease. Am J Kidney Dis 1995; 25:103-106.

10 Bennett P, Haffner S, Kasiske B, Keane W, Mogensen C, Parving HH, Steffes M, Striker $\mathrm{G}$ : Screening and management of microalbuminuria in patients with diabetes mellitus: Recommendations to the scientific advisory board of the national kidney foundation from an Ad Hoc Committee of the Council on Diabetes Mellitus of the National Kidney Foundation. Am J Kidney Dis 1995;25:107-112.

11 DCCT Research Group: The effect of intensive treatment on the development and progression of long-term complications in insulin-dependent diabetes mellitus. N Engl J Med 1993;329: 977-986.

12 Brazy P, Stead W, Fitzwilliam J: Progression of renal insufficiency: Role of blood pressure. Kidney Int 1989;35:670-674.

13 Kasiske B, Kalil R, Ma J, Liao M, Keane W: Effect of antihypertensive therapy on the kidney in patients with diabetes: A meta-regression analysis. Ann Intern Med 1993;118:129138.

14 Klahr S, Levey A, Beck G, Caggiula A, Hunsicker L, Kusek J, Striker G, MDRD Study Group: The effects of dietary protein restriction and blood pressure control on progression of chronic renal disease. N Engl J Med 1994; 330:877-884.

15 Pettinger W, Lee $\mathrm{H}$, Reisch J, Mitchell $\mathrm{H}$ : Long-term improvement in renal function after short-term strict blood pressure control in hypertensive nephrosclerosis. Hypertension 1989;13:766-772.
16 Lewis E, Hunsicker L, Bain R, Rohde R: The effect of angiotensin-converting enzyme inhibition on diabetic nephropathy. N Engl J Med 1993;329:1456-1462.

17 Lim VS, DeGowin RL, Zavala D, Kirchner PT, Abels R, Perry P, Fangman J: Recombinant human erythropoietin treatment in pre-dialysis patients. A double-blind placebo-controlled trial. Ann Intern Med 1989;110:108-114.

18 Revicki DA, Brown RE, Feeny DH, Henry D, Teehan BP, Rudnick MR, Benz RL: Healthrelated quality of life associated with recombinant human erythropoietin therapy for predialysis chronic renal disease patients. Am J Kidney Dis 1995;25:548-554

19 Slatopolsky E, Robson AM, Elkan I, Bricker NS: Control of phosphate excretion in uremic man. J Clin Invest 1968;47:1865-1874.

20 Pitts TO, Piraino BH, Mitro R, Chen TC, Segre GV, Greenberg A, Puschett JB: Hyperparathyroidism and 1,25-dihydroxyvitamin $\mathrm{D}$ deficiency in mild, moderate and severe renal failure. J Clin Endocrinol Metab 1988;67:876881.

21 Hamdy NA, Kanis JA, Beneton MN, Brown CB, Juttmann JR, Jordans JG, Josse S, Meyrier A, Lins RL, Fairey IT: Effect of alfacalcidol on natural course of renal bone disease in mild to moderate renal failure. BMJ 1995;310:358363.

22 Campbell J, Ewigman B, Hosokawa M, Stone JV: The timing of referral of patients with endstage renal disease. Dial Transplant 1989;18: 660-686. 
23 Kausz A, Khan S, Abichandani R, Kazmi W, Obrador G, Ruthazer R, Pereira B: Management of patients with chronic renal failure insufficiency in the Northeastern United States. J Am Soc Nephrol 2001;12:1501-1507.

24 Eadington DW: Delayed referral for dialysis Nephrol Dial Transplant 1996;11:2124-2126.

25 Hannah R, Levin N, London R, Osheroff W: Renal disease in the managed care setting. Am J Kidney Dis 1999;33(suppl 1):1-24.

26 Group SM: eManaged Care Digest. Aventis Pharmaceuticals, 2001.

27 STATA 6.0 (program). College Station/Tex, STATA Corp, 1999.
28 Nissenson A, Collins A, Hurley J, Petersen H, Pereira B, Steinberg E: Opportunities for improving the care of patients with chronic renal insufficiency: Current practice patterns. J Am Soc Nephrol 2001;12:1713-1720.

29 Peters A, Legorreta A, Ossborio R, Davidson M: Quality of outpatient care provided to diabetic patients. A Health Maintenance Organization experience. Diabetes Care 1996;19:601606.

30 Burt V, Cutler J, Higgins M, Horan M, Labarthe D, Whelton P, Brown C, Roccella E: Trends in the prevalence, awareness, treatment and control of hypertension in the adult US population. Data from the health examination surveys, 1960-1991. Hypertension 1995;26: 60-69.

31 Marshall C, Bluestein M, Chapin C, Davis T, Gersten J, Harris C, Hodgin A, Larsen W, Rigberg H, Krishnaswami V, Darling B: Outpatient management of diabetes mellitus in five Arizona Medicare managed care plans. Am J Med Qual 1996;11:87-93.
32 Sikka R, Waters J, Moore W, Sutton D, Herman W, Aubert R: Renal assessment practices and the effect of nurse case management of Health Maintenance Organization patients with diabetes. Diabetes Care 1999;22:1-6.

33 Martin T, Selby J, Zhang D: Physician and patient prevention practices in type 2 diabetes in a large urban managed care organization. Diabetes Care 1995;18:1124-1132.

34 Miller K, Hirsch I: Physicians' practices in screening for the development of diabetic nephropathy and the use of glycosylated hemoglobin levels. Diabetes Care 1994;17:1495-1497.

35 Hennekens C, Buring J: Epidemiology in Medicine, ed 1. Boston, Little, Brown, 1987, pp 272-286. 